\title{
CULTIVO DA RÚCULA EM SUBSTRATO DE FIBRA DE COCO SOB SOLUÇÃO NUTRITIVA SALINA
}

\author{
Rafaelly Suzanye da Silva Santos ${ }^{1 *}$, Nildo da Silva Dias², Sergio Nascimento Duarte ${ }^{3}$, \\ Carlos José Gonçalves de Souza Lima ${ }^{4}$, Cleyton dos Santos Fernandes ${ }^{5}$, Jarbas Honorio de \\ Miranda $^{3}$ \\ 1 Professora Assistente, Universidade Federal Rural da Amazônia (UFRA), Belém - PA. *E-mail: \\ rafaelly_santos@yahoo.com.br \\ 2 Professor Associado, Centro de Ciências Agrárias, Universidade Federal Rural do Semi-Árido (UFERSA), \\ Mossoró - RN. \\ 3 Professor Associado, Departamento de Engenharia de Biossistemas, Escola Superior de Agronomia "Luiz de \\ Queiroz" (ESALQ), Piracicaba - SP. \\ ${ }^{4}$ Professor adjunto, Centro de Ciências Agrárias, Departamento de Engenharia Agrícola e Solos, Universidade \\ Federal do Piauí (UFPI), Teresina - PI. \\ ${ }^{5}$ Engenheiro Agrônomo, Universidade Federal Rural do Semi-Árido (UFERSA), Mossoró - RN.
}

RESUMO: Em função da baixa disponibilidade de água doce para a agricultura, o uso de água salina na produção de alimentos e a adoção do sistema hidropônico são alternativas para o semiárido. É necessário buscar alternativas para o uso condizente dessas águas com seu maior aproveitamento na produção vegetal e reduzir os impactos ambientais. Assim, o presente trabalho teve como objetivo avaliar o efeito da salinidade da solução nutritiva para rúcula (Eruca sativa L. cv. "Cultivada") cultivada em substrato de fibra de coco sob condições protegidas. Foi utilizado o delineamento em blocos casualizados, arranjados em esquema fatorial $4 \times 4$, com quatro tipos de solução nutritiva de composição salina, adicionadas de $\mathrm{NaCl}\left(\mathrm{S}_{\mathrm{T}}=2,0 ; \mathrm{S}_{1}=3,5 ; \mathrm{S}_{2}=4,5\right.$ e $\left.\mathrm{S}_{3}=5,5 \mathrm{dS} \mathrm{m}^{-1}\right)$, aplicadas em quatro épocas de desenvolvimento (primeira, segunda, terceira e quarta semana após o transplantio), com quatro repetições. Os resultados indicam que o aumento da salinidade da solução nutritiva não proporcionou redução para altura das plantas e número de folhas, sendo os teores de $\mathrm{Na} \mathrm{e} \mathrm{Cl}$ nas folhas classificado como aceitável para alimentação humana.

Palavras-chave: Eruca sativa L. Hidroponia. Salinidade.

\section{CULTIVATION OF SALAD ROCKET IN COCONUT FIBER UNDER SALINE NUTRIENT SOLUTION}

\begin{abstract}
Due to the low availability of flesh water for agriculture, the use of salinity water in production and adoption of hydroponically are alternatives to the semi-arid region. It is necessary to find alternatives to the use of these waters consistent with its greater use in crop production decreasing environmental impacts. This study aimed to evaluate the effect of the saline nutrient solution of salad rocket (Eruca sativa L. cv. "Cultivated") growth in coconut fiber substrate under protected conditions. The randomized block design was used, arranged in a $4 \times 4$ factorial scheme, with four types of nutritive solution of saline composition added $\mathrm{NaCl}\left(\mathrm{S}_{\mathrm{T}}=2,0 ; \mathrm{S}_{1}=3,5 ; \mathrm{S}_{2}=45\right.$ and $\left.\mathrm{S}_{3}=5,5 \mathrm{dS} \mathrm{m}^{-1}\right)$ applied in four
\end{abstract}


seasons of development (first, second, third and fourth week after planting), with four replications. The results show that increasing saline nutrient solution provided no reduction for plant height and number of leaves, and the content of $\mathrm{Na}$ and $\mathrm{Cl}$ in leaves classified as acceptable for human consumption.

Key words: Eruca sativa L. Hydroponics. Salinity.

\section{INTRODUÇÃO}

No cenário atual, em função da baixa disponibilidade de água para a agricultura, diversas pesquisas e tecnologias devem ser geradas para enfrentar essas limitações. Umas das alternativas é o uso de águas salinas na produção de alimentos e a adoção do sistema hidropônico que respondem as particularidades da região semiárida.

Nos últimos anos, algumas pesquisas têm avaliado a viabilidade do aproveitamento de águas salinas em várias espécies em sistema hidropônico (SILVA, 2009; DIAS et al., 2010; DIAS et al., 2011; SILVA et al., 2012; SANTOS et al., 2012). Estes estudos têm indicado que, em condições salinas, as plantas crescidas em sistema hidropônico têm melhor desempenho que no cultivo em solo, devido à ausência do potencial mátrico que é uma das causas da diminuição da energia livre da água (SOARES et al., 2007).

Quanto aos substratos utilizados nos sistemas hidropônicos, Carrijo et al. (2002) verificaram uma superioridade da fibra de coco por apresentar propriedades físicas favoráveis, tais como reação inerte com os nutrientes da adubação, durabilidade das suas características físicas, possibilidade de esterilização, além da abundância da matéria prima, que é renovável e apresenta baixo custo para o produtor.

Uma das principais hortaliças folhosas produzidas no Brasil via hidroponia, a rúcula (Eruca sativa L.) possui ciclo curto, apresenta rico conteúdo nutricional (K, S, Fe, proteínas, vitaminas A e C), alta produção por área e ampla aceitabilidade pelo mercado consumidor, devido às suas diferenciadas características organolépticas (REGHIN et al., 2004; AMORIM et al., 2007).

Levando-se em consideração estes aspectos, objetivou-se avaliar a viabilidade da utilização de águas salinas sobre o cultivo hidropônico no crescimento e na composição mineral no tecido vegetal de rúcula em diferentes estádios de desenvolvimento da cultura, preparada com adição de $\mathrm{NaCl}$.

\section{MATERIAL E MÉTODOS}

O experimento foi conduzido nos meses de novembro a dezembro de 2009, em ambiente protegido situado no Departamento de Engenharia de Biossistemas da Escola Superior de Agricultura "Luiz de Queiroz", ESALQ-USP, Piracicaba - SP, $\left(22^{\circ} 42\right.$ ' de latitude sul e $47^{\circ} 38^{\prime}$ 'de longitude Oeste, a $540 \mathrm{~m}$ de altitude). 
O substrato usado foi o Golden-Mix ${ }^{\circledR}$, composto da mistura de $50 \%$ de substrato de textura grosseira, mais $50 \%$ de substrato de textura granulada, elaborado a partir do mesocarpo do coco, incorporando toda porção fibrosa do mesmo. Suas características são apresentadas na Tabela 1, conforme análise realizada no Departamento de Solos e Nutrição de Plantas da ESALQ/USP (TAVARES, 2005).

Tabela 1. Resultados de análises do material orgânico da fibra de coco (ESALQ/USP).

\begin{tabular}{|c|c|c|c|c|c|c|c|c|c|c|c|c|c|}
\hline $\mathrm{Cu}$ & $\mathrm{Mn}$ & $\mathrm{Zn}$ & $\mathrm{Fe}$ & B & $\mathrm{Na}$ & $\mathrm{N}$ & $\mathrm{P}$ & $\mathrm{k}$ & $\mathrm{Ca}$ & $\mathrm{Mg}$ & S & $\mathrm{pH}$ & $\mathrm{C} / \mathrm{N}$ \\
\hline--- & 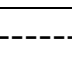 & $-m g$ & $g^{-1}$ & & ---- & & & ל---- & 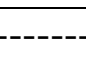 & & --- & & \\
\hline 3 & 16 & 8 & 822 & 8 & 160 & 0,2 & 0,01 & 0,31 & 0,11 & 0,03 & 0,03 & $0,01 \mathrm{M}$ & $69 / 1$ \\
\hline
\end{tabular}
Fonte: Adaptado de Tavares (2005).

O delineamento estatístico utilizado foi o de blocos casualizados completos, com quatro repetições, em esquema fatorial 4x4 (níveis de salinidade da solução nutritiva $\mathrm{x}$ épocas de aplicação) sendo cada bloco composto por 16 vasos. Foi feita a rotação dos vasos durante o ciclo. As plantas de rúcula, cv. Cultivada, foram nutridas com solução nutritiva com salinidade de 2,0 ( $\mathrm{S}_{\mathrm{T}}$ - testemunha); $\mathrm{S}_{1}-3,5 ; \mathrm{S}_{2}-4,5 ;$ e $\mathrm{S}_{3}-5,5 \mathrm{dS} \mathrm{m}^{-1}$, aplicadas em quatro épocas de desenvolvimento (primeira, segunda, terceira e quarta semana após o transplantio).

Tabela 2. Concentração de nutrientes e quantidades de fertilizantes para o preparo de $1 \mathrm{~m}^{3}$ de solução nutritiva para o cultivo de rúcula (Eruca sativa $\mathrm{L}$ ).

\begin{tabular}{|c|c|c|c|c|c|c|c|c|c|c|c|c|}
\hline \multirow{2}{*}{ Fertilizante } & & $\mathrm{NH}_{4} \mathrm{NO}_{3}$ & $\mathrm{P}$ & $\mathrm{K}$ & $\mathrm{Ca}$ & $\mathrm{Mg}$ & $\begin{array}{ll}S & B \\
\end{array}$ & $\mathrm{Cu}$ & $\mathrm{Fe}$ & $\mathrm{Mn}$ & Mo & $\mathrm{Zn}$ \\
\hline & \multicolumn{12}{|c|}{ 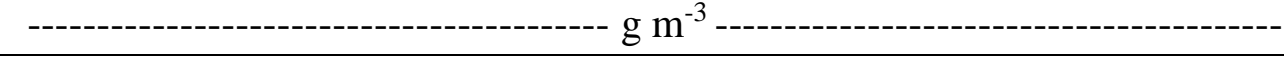 } \\
\hline $\begin{array}{l}\text { Nitrato de } \\
\text { cálcio }\end{array}$ & 750 & $7,5108,75$ & & & 142,5 & & & & & & & \\
\hline $\begin{array}{l}\text { Nitrato de } \\
\text { potássio }\end{array}$ & 500 & 65 & & 182,5 & & & & & & & & \\
\hline $\begin{array}{l}\text { Fosfato } \\
\text { monoamônico }\end{array}$ & 150 & 16,5 & 39 & & & & & & & & & \\
\hline $\begin{array}{l}\text { Sulfato de } \\
\text { magnésio }\end{array}$ & 400 & & & & & 40 & 52 & & & & & \\
\hline $\begin{array}{l}\text { Sulfato de } \\
\text { cobre }\end{array}$ & 0,15 & & & & & & & 0,02 & & & & \\
\hline $\begin{array}{l}\text { Sulfato de } \\
\text { zinco }\end{array}$ & 0,3 & & & & & & & & & & & 0,07 \\
\hline $\begin{array}{l}\text { Sulfato de } \\
\text { manganês }\end{array}$ & 1,5 & & & & & & & & & 0,39 & & \\
\hline Ácido bórico & 1,8 & & & & & & 0,31 & & & & & \\
\hline $\begin{array}{l}\text { Molibdato de } \\
\text { sódio }\end{array}$ & 0,15 & & & & & & & & & & 0,06 & \\
\hline $\begin{array}{c}\text { Fe-EDTA - } \\
13 \% \mathrm{Fe}\end{array}$ & 16 & & & & & & & & 2,08 & & & \\
\hline
\end{tabular}
Fonte: Adaptado de Furlani (1998). 
Todas as parcelas receberam a mesma quantidade de água e nutrientes até a colheita. As soluções nutritivas foram preparadas na mesma época e utilizadas até o final do ciclo, com exceção da solução nutritiva testemunha, que precisou ser feita novamente no meio do ciclo. A solução nutritiva utilizada tanto na produção das mudas quanto no cultivo foi baseada em Furlani (1998), sendo caracterizada pela CE de 2,0 dS m${ }^{-1}$ e elaborada a partir de água com baixa salinidade $\left(0,20 \mathrm{dS} \mathrm{m}^{-1}\right)$, de acordo com a Tabela 2. A variação da salinidade entre os tratamentos foi obtida com a aplicação de $\mathrm{NaCl}$ à solução nutritiva. Para a Testemunha não foi aplicado o $\mathrm{NaCl}$.

A irrigação foi feita com base no consumo hídrico das plantas nos vasos para cada período. Depois de hidratada a fibra, os vasos foram pesados diariamente e, a partir da pesagem foi realizada a irrigação com base na quantidade de água absorvida e drenada. A quantidade de água utilizada era suficiente para a manutenção da planta, não havendo drenagem, portanto, não houve reutilização desta. A quantidade de água a ser utilizada diariamente foi medida em proveta, para melhor mensuração. Assim, foram aplicadas as dosagens de $\mathrm{NaCl}$ de acordo com o pré-estabelecido para os determinados níveis.

As sementes foram semeadas em bandejas de poliestireno expandido com 375 células, com substrato de vermiculita. Na semeadura, colocaram-se dez sementes, em média, por célula, a 0,04 $\mathrm{m}$ de profundidade, sendo cobertas com uma camada fina do substrato. Após o desbaste foram mantidas seis plântulas por célula.

Os vasos com capacidade de $0,83 \mathrm{dm}^{3}$ foram preenchidos com $140 \mathrm{~g}$ de substrato de fibra de coco. Após o enchimento, fez-se a hidratação da fibra, colocando-se os vasos imersos em água até a saturação e, em seguida, esperou-se a drenagem natural. $\mathrm{Na}$ sequência realizou-se o transplantio, com as mudas apresentando 4 a $5 \mathrm{~cm}$ de altura e quatro folhas (incluindo os cotilédones) com emissão da quinta.

Os tratamentos foram iniciados três dias após o transplantio, com intuito de amenizar o estresse das plantas e obter melhor adaptação. O desbaste foi realizado cinco dias após o transplantio, sendo eliminadas as plântulas em excesso, deixando-se seis mudas por vaso.

Por ocasião da colheita, aos 32 dias após o transplantio (DAT), foram medidas as alturas das plantas por unidade amostral, desde o nível do substrato até a inflexão da folha, utilizando-se régua graduada em centímetros (HARDER, 2004). Foram contados o número de folhas verdes maiores de 3,0 cm de comprimento, desprezando-se as amareladas e/ou secas, partindo-se das folhas basais até a última folha aberta, de cada unidade amostral. Determinou-se no laboratório de Tecidos Vegetais do Departamento de Ciência do Solo da ESALQ-USP, concentrações totais dos elementos $\mathrm{Cl}$ e $\mathrm{Na}$ contidos nas amostras de folhas, após secagem em estufa com circulação forçada de ar a $70^{\circ} \mathrm{C}$.

Os resultados do experimento foram submetidos à análise de variância. $\mathrm{O}$ fator quantitativo relativo aos níveis de salinidade da solução nutritiva (CEs) foi analisado estatisticamente por meio de regressão polinomial (linear e quadrática), enquanto que o fator qualitativo relativo às épocas (semanas) foi analisado por meio do teste Tukey em $5 \%$ de 
probabilidade. Os fatores que apresentaram interação significativa realizaram-se o desdobramento da interação dentro de cada fator e teste F.

\section{RESULTADOS E DISCUSSÃO}

De acordo com a análise de variância, não houve efeitos significativos ( $p>0,05)$ dos fatores salinidade, tempo de aplicação e interação salinidade x época para o parâmetro altura da planta e número de folha.

Podem-se verificar na Figura 1 os valores médios de altura das plantas ao longo do ciclo, em função das diferentes épocas de aplicação da salinidade da solução nutritiva. As plantas não apresentaram efeitos $(\mathrm{p}>0,05)$ da salinidade da solução nutritiva para nenhuma época de aplicação.
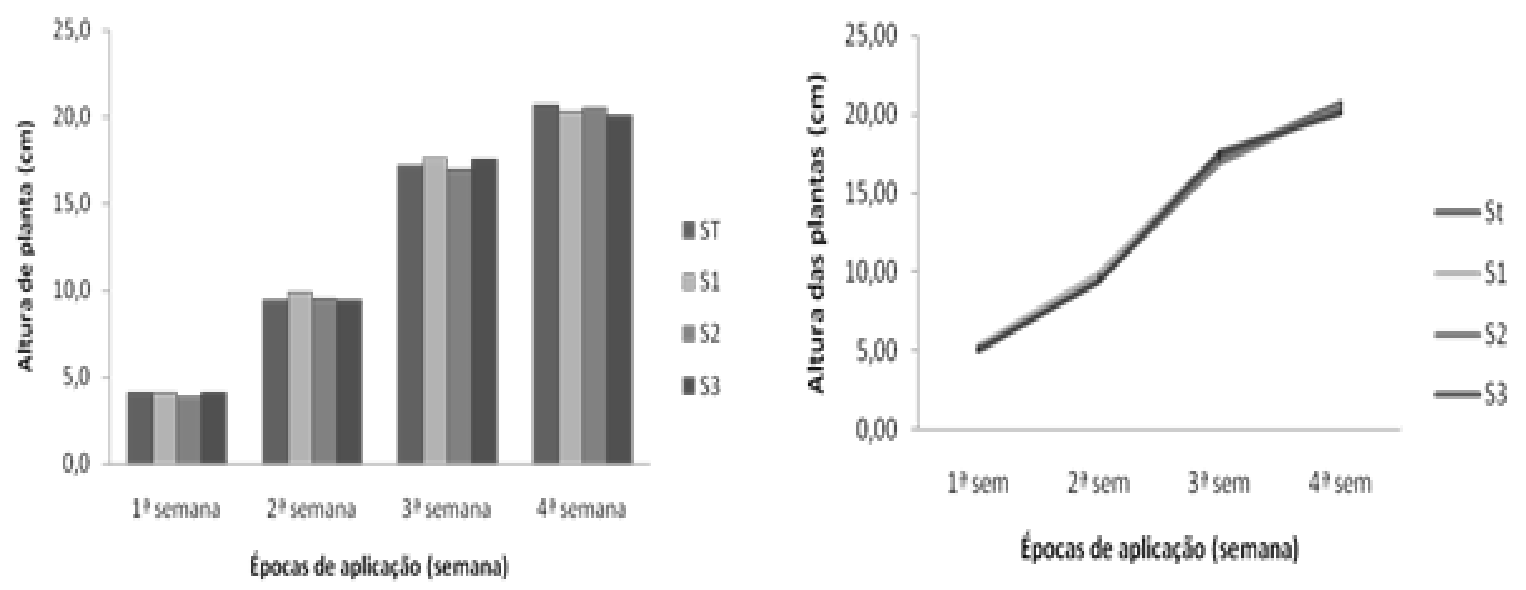

$\mathrm{St}=$ testemunha $\left(2,0 \mathrm{dS} \mathrm{m}^{-1}\right) ; \mathrm{S}_{1}=3,5 \mathrm{dS} \mathrm{m}^{-1} ; \mathrm{S}_{2}=4,5 \mathrm{dS} \mathrm{m}^{-1} ; \mathrm{S}_{3}=5,5 \mathrm{dS} \mathrm{m}^{-1}$.

Figura 1. Alturas médias das plantas ao longo do ciclo em função das épocas de aplicação da solução nutritiva salina $(\mathrm{S})$.

Não houve diferença no crescimento da rúcula em função da salinidade da solução nutritiva para as épocas de aplicação, mostrando que o crescimento foi praticamente o mesmo em todas as épocas analisadas, independente dos níveis salinos (Figura 1). Este fato demonstra que não houve influência deste fator sobre o parâmetro de altura das plantas em nenhuma das medições efetuadas. Analisando a perda de rendimento relativo por incremento unitário da CEs desde o menor nível, de 2,0 dS m${ }^{-1}$, para os níveis maiores de salinidade foram observadas reduções de $8,41 \%$ do último nível em relação ao primeiro nível.

Silva et al. (2011) trabalhando com rúcula em sistema hidropônico NFT (NFT = sigla de Nutrient Film Technique. Sua tradução para o português é técnica do filme nutriente), avaliando diferentes fontes de águas salinas, variando de 0,2 a 5,2 $\mathrm{dS} \mathrm{m}^{-1}$, obteve efeito significativo para altura de plantas; além de perdas quantitativas decorrentes do aumento da salinidade da água, também foram registradas perdas qualitativas que não permitiram considerar a produção de massa de matéria fresca como o rendimento da rúcula. Em outro 
trabalho, avaliando o desenvolvimento de variedades de girassol irrigado com água salina, também houve um efeito significativo do fator salinidade da água de irrigação para a variável altura da planta em todas as épocas de avaliação (TRAVASSOS et al., 2012).

Ressaltando a não significância entre os fatores salinidade da solução nutritiva e épocas de aplicação, tem-se que, para o parâmetro altura de plantas pode-se utilizar solução nutritiva de alta salinidade (até 5,5 $\mathrm{dS} \mathrm{m} \mathrm{m}^{-1}$ ) quando se dispõe apenas desta, para se cultivar rúcula em substrato de fibra de coco sem perdas na altura de plantas e sem a necessidade de manejo rigoroso da água salobra (fração de lixiviação, mistura das águas e/ou aplicação em estádio de desenvolvimento diferenciado).

Em estudo realizado por Alves (2011) não foi observado reduções na variável altura de plantas no cultivo de rúcula, com o aumento da salinidade da água, sendo que as mesmas apresentaram valores médios de 25,49, sendo esse comportamento atribuído ao curto período de exposição das plantas à salinidade, pois as mesmas foram colhidas aos 16 dias após o transplantio (DAT).

Ao final do ciclo as plantas apresentaram altura média de $25,7 \mathrm{~cm}$, estando acima da altura padrão comercial. Segundo Minami e Tessarioli Neto (1998), para a comercialização, as folhas de rúcula, devem possuir de 15 a $20 \mathrm{~cm}$ de comprimento, bem desenvolvidas, verdes e frescas, livres de pragas ou doenças. Porém, o mercado consumidor dessa hortaliça é muito variável e regionalizado apresentando exigências, supridas apenas, por diferentes produtos. Certas regiões preferem para o consumo "in natura" folhas grandes e outras apreciam folhas pequenas. Além disso, a forma de utilização dessa hortaliça também é condicionada ao seu tamanho.

O número de folhas nas plantas de rúcula não sofreu efeito significativo $(\mathrm{p}>0,05)$ da concentração salina da solução hidropônica, apresentando um valor médio de 41,25 folhas em cada unidade amostral.

Quando se analisou os níveis de salinidades, o número de folhas não diferiu do tratamento inicial ao mais salino, tendo-se apenas um decréscimo de 3,43\% quando foi irrigado com o nível de 4,5 dS m${ }^{-1}$, em relação ao tratamento testemunha. O mesmo também foi verificado por Silva et al. (2012), não havendo também alterações no número de folhas de rúcula pelo aumento da salinidade da solução nutritiva. Silva (2009) observou que não houve equação que ajustasse ao parâmetro número de folhas, demostrando que a mesma respondeu de forma aleatória ao incremento de condutividade elétrica da solução aplicada no cultivo hidropônico de rúcula.

Silva et al. (2012) observaram uma redução na quantidade de folhas de rúcula por tratamento na ordem de 3,34\% em função do aumento da salinidade em que as plantas foram submetidas, sendo com a adição de $\mathrm{NaCl}$, o número de folhas médio foi de 4,28 folhas por planta.

Com relação a concentrações totais dos elementos $\mathrm{Cl}$ e $\mathrm{Na}$ contidos no tecido foliar da rúcula para os níveis de salinidade da solução nutritiva e épocas de aplicação, verificou-se 
que com o aumento da salinidade da solução nutritiva houve incremento na absorção de $\mathrm{Cl}$ e $\mathrm{Na}$ nas folhas (Figura 2), demonstrando que quanto maior a quantidade de $\mathrm{NaCl}$ da solução nutritiva maior o acúmulo nas folhas do sal ao final do ciclo.
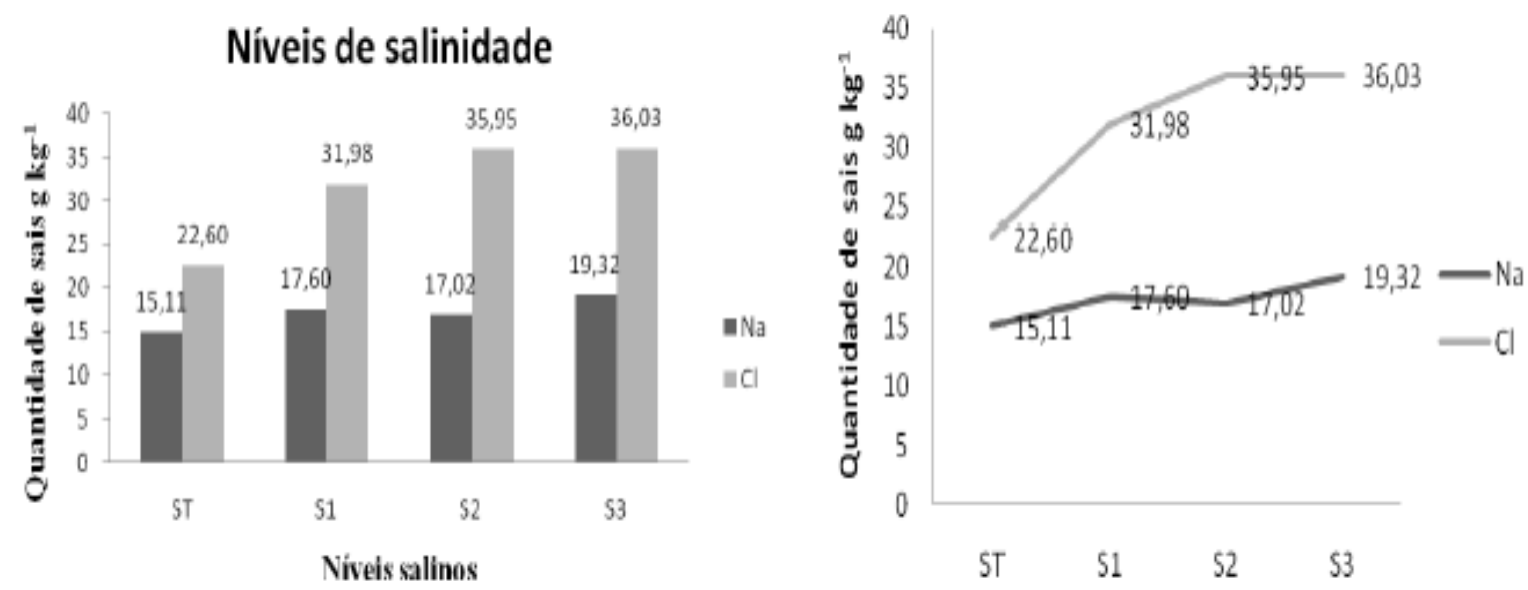

$\mathrm{St}=$ testemunha $\left(2,0 \mathrm{dS} \mathrm{m}^{-1}\right) ; \mathrm{S}_{1}=3,5 \mathrm{dS} \mathrm{m}^{-1} ; \mathrm{S}_{2}=4,5 \mathrm{dS} \mathrm{m}^{-1} ; \mathrm{S}_{3}=5,5 \mathrm{dS} \mathrm{m}^{-1}$.

Figura 2. Teores de $\mathrm{Na}$ e $\mathrm{Cl}$ nas folhas de rúcula cultivada em fibra de coco para os diferentes níveis de salinidade da solução nutritiva $(\mathrm{S})$.

Segundo Paulus et al. (2012), houve incremento do nível de salinidade na água influenciando aumentos significativos nas concentrações de sódio e de cloro nas folhas. As concentrações de cloro foram superiores às de sódio, por sua mobilidade e transporte elevado como ânion livre na planta. Fernandes et al. (2002) também verificaram maior acúmulo de cloro do que de sódio em pupunheira, em condições salinas

Savvas et al. (2007), trabalharam com a cultura do pimentão submetida a dois regimes

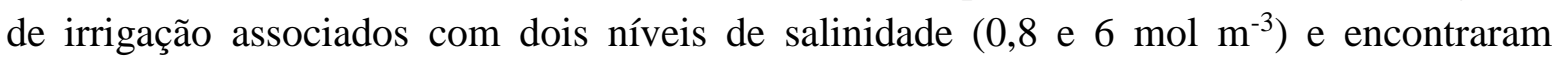
acúmulo crescente nas folhas jovens no nível mais salino da água de irrigação $\left(6 \mathrm{~mol} \mathrm{~m}^{-3}\right)$ introduzida no sistema hidropônico de ciclo fechado.. Além disso, os autores concluíram que os níveis de $\mathrm{Na}$ e $\mathrm{Cl}$ na solução drenada aumentou com o tempo devido à acumulação progressiva, em um padrão semelhante com o da CE da solução nutritiva. Entretanto, as diferenças nas concentrações de $\mathrm{Na}$ e $\mathrm{Cl}$ entre a baixa e alta frequência de irrigação foram estatisticamente significativa apenas para os níveis altos de salinidade.

Aktas et al. (2006), estudando a variação genética de 102 genótipos de pimentão (Capsicum annuum) tolerantes a $100 \mathrm{mM}$ de cloreto de sódio $(\mathrm{NaCl})$ em solução nutritiva, obtiveram resultados significativos quando o $\mathrm{NaCl}$ foi fornecido; os genótipos testados foram mais ou menos similar na concentração de $\mathrm{Na}$, e quando houve fornecimento de $\mathrm{NaCl}$, os genótipos sensíveis com maior dano foliar tiveram maior concentração de $\mathrm{Na}$ nas folhas. A concentração de $\mathrm{Na}$ para o tratamento com $\mathrm{NaCl}$, foi significativamente correlacionado com a severidade dos sintomas foliares causado pela toxidez de $\mathrm{NaCl}$. Este tratamento exerceu um efeito reduzido na concentração de $\mathrm{K}$ nas plantas, e esta redução 
ficou mais evidente nos genótipos sensíveis. Também reduziu a concentração de Ca na planta.

Como observado na Figura 3, a alta salinidade da solução nutritiva aplicado em diferentes épocas resultou em maior concentração de $\mathrm{Cl}$ nas folhas do que $\mathrm{Na}$, tendo decréscimo no D2 (segunda semana de aplicação) e um leve acúmulo na concentração de $\mathrm{Na}$, no decorrer do ciclo.
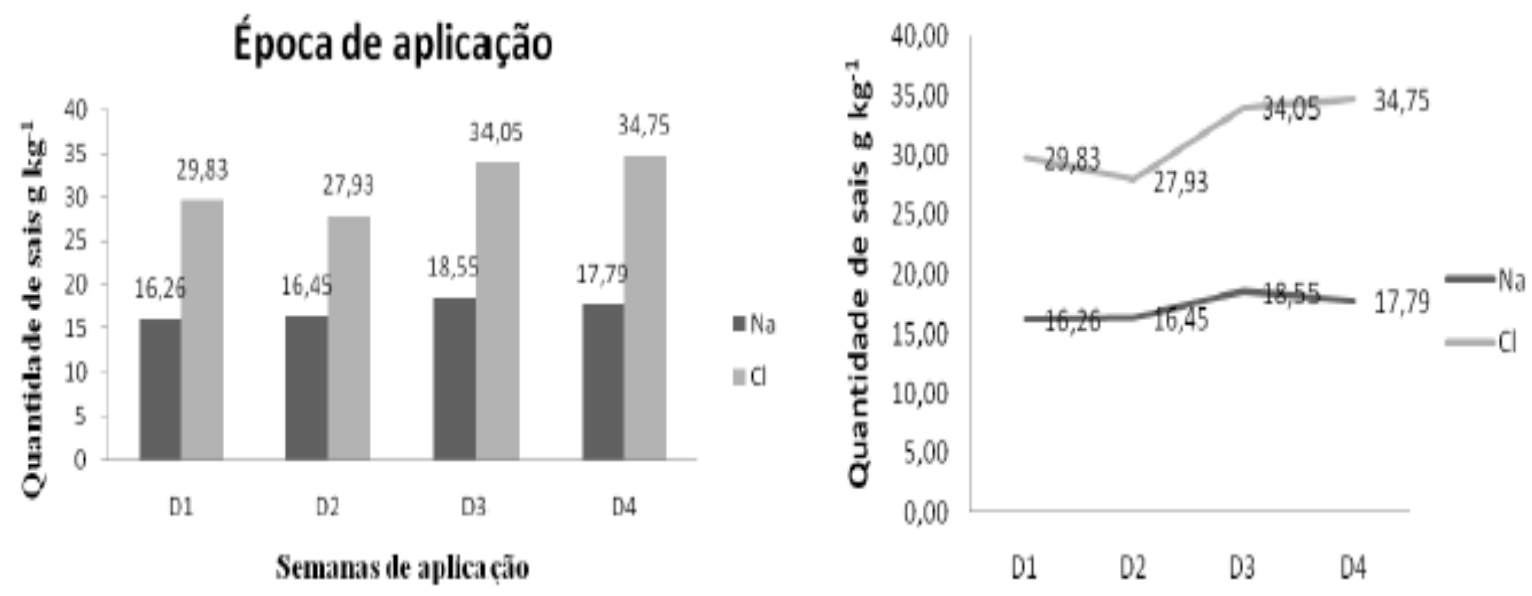

D1 = semana 1; D2 = semana 2; D3 = semana 3; D4 = semana 4

Figura 3. Teores de $\mathrm{Na}$ e $\mathrm{Cl}$ nas folhas de rúcula cultivada em fibra de coco para as épocas de aplicação (Semanas - D) da solução nutritiva.

Quando aplicado $\mathrm{NaCl}$ no início do ciclo, os efeitos do $\mathrm{Na}$ foram mais leves no início em relação ao teor acumulado no final, observação semelhante com relação ao $\mathrm{Cl}$, tendo-se um decréscimo no acúmulo quando aplicado na segunda semana de cultivo. A maior concentração de $\mathrm{Na}$ nas folhas foi observado quando o tratamento ocorreu na $3^{\mathrm{a}}$ semana, enquanto que o $\mathrm{Cl}$ teve maior concentração quando aplicado na $4^{\mathrm{a}}$ semana.

Assim, com base nos resultados, ao utilizar $\mathrm{NaCl}$ na produção hidropônica de rúcula o mais indicado será usar a solução na $2^{\mathrm{a}}$ semana de cultivo, visto que os danos e perdas serão relativamente pequenos.

\section{CONCLUSÃO}

As variáveis altura das plantas e número de folhas não foram afetados pelo incremento da salinidade da solução nutritiva utilizada no cultivo de rúcula em fibra de coco.

Os teores de $\mathrm{Na}$ e $\mathrm{Cl}$ nas folhas são aceitáveis ou permitido, para alimentação humana.

É possível obter produções com rendimentos satisfatórias utilizando solução nutritiva salinas no cultivo de rúcula em substrato de fibra de coco. 


\section{REFERÊNCIAS BIBLIOGRÁFICAS}

AKTAS, H.; ABAK, K.; CAKMAK, I. Genotypic variation in the response of pepper to salinity. Scientia Horticulturae, Amsterdam, v. 110, n. 3, p.260-266, 2006.

ALVES, M. S.; SOARES, T. M.; SILVA, L. T.; FERNANDES, J. P.; OLIVEIRA, M. L. A.; PAZ, V. P. S. Estratégias de usos de águas salobras no cultivo de hortaliças folhosas em sistema hidropônico NFT. Revista Brasileira de Engenharia Agrícola e Ambiental, Campina Grande, v. 15, n. 5, p.491-498, 2011.

AMORIM H. C.; HENZ G. P.; MATTOS L. M. Identificação dos tipos de rúcula comercializados no varejo do Distrito Federal. Brasília: Embrapa Hortaliças, 2007. 13 p. (Embrapa Hortaliças. Boletim de Pesquisa e Desenvolvimento da Embrapa Hortaliças, 34).

CARRIJO, O. A.; LIZ, R. S.; MAKISHIMA, N. Fibra da casca do coco verde como substrato agrícola. Horticultura Brasileira, Brasília, v. 20, n. 4, p.533-535, 2002.

DIAS, N. S.; LIRA, R. B.; BRITO, R. F.; SOUZA NETO, O. N.; FERREIRA NETO, M.; OLIVEIRA, A. M. Produção de melão rendilhado em sistema hidropônico com rejeito da dessalinização de água em solução nutritiva. Revista Brasileira de Engenharia Agrícola e Ambiental, Campina Grande, v. 14, n. 7, p.755-761, 2010.

DIAS, N. S.; JALES, A. G. O.; SOUSA NETO, O. N.; GONZAGA, M. I. S.; QUEIROZ, I. S. R.; PORTO, M. A. F. Uso de rejeito da dessalinização na solução nutritiva da alface, cultivada em fibra de coco. Revista Ceres, Viçosa, v. 58, n. 5, p.632-637, 2011.

FERNANDES, A. R.; CARVALHO, J. G.; CURI, N.; PINTO, J. E. B. P.; GUIMARÃES, P. T. G. Nutrição mineral de mudas de pupunheira sob diferentes níveis de salinidade. Pesquisa Agropecuária Brasileira, Brasília, v. 37, n. 11, p.1613-1619, 2002.

HARDER, W. C. Produção e renda bruta de rúcula (Eruca sativa Mill.) 'Cultivada' e de almeirão (Cichorium intybus L.) 'Amarelo', em cultivo solteiro e consorciado. 2004. 26 f. Dissertação (Mestrado em Agronomia) - Universidade Federal de Minas Gerais, Dourados, 2004.

FURLANI, P. R. Instruções para o cultivo de hortaliças de folhas pela técnica de hidroponia NFT. Campinas: Instituto Agronômico, 1998. 30 p. (Boletim Técnico, 168).

MINAMI, K.; TESSARIOLI NETO, J. A. Cultura da rúcula. Piracicaba: ESALQ/USP, 1998. 19 p.

PAUluS, D.; PAUluS, E.; NAVA, G. A.; MOURA, C. A. Crescimento, consumo hídrico e composição mineral de alface cultivada em hidroponia com águas salinas. Revista Ceres, Viçosa, v.59, n.1, p.110-117, 2012.

REGHIN M. Y.; OTTO R. F.; VINNE, J. V. D. Efeito da densidade de mudas por célula e do volume da célula na produção de mudas e cultivo da rúcula. Ciência e Agrotecnologia, Lavras, v. 28, n. 2, p.287-295, 2004. 
SANTOS, R. S. S.; DIAS, N. S.; DUARTE, S. N.; LIMA, C. J. G. S. Uso de águas salobras na produção de rúcula cultivada em substrato de fibra de coco. Revista Caatinga, Mossoró, v. 25, n. 1, p.113-118, 2012.

SAVVAS, D.; STAMATI, E.; TSIROGIANNIS, I. L.; MANTZOS, N.; BAROUCHAS, P. E.; KATSOULAS, N.; KITTAS, C. Interactions between salinity and irrigation frequency in greenhouse pepper grown in closed-cycle hydroponic systems. Agricultural and Water Management, Amsterdam, v. 91, n. 1-3, p.102-111, 2007.

SILVA, A. O.; SOARES, T. M.; SILVA, E. F. F.; SANTOS, A. N.; KLAR, A. E. Consumo hídrico da rúcula em cultivo hidropônico NFT utilizando rejeitos de dessalinizador em Ibimirim-PE. Irriga, Botucatu, v. 17, n. 1, p.114-125, 2012.

SILVA, A. O.; SILVA, D. J. R.; SOARES, T. M.; SILVA, E. F. F.; SANTOS, A. N.; ROLIM, M. M. Produção de rúcula em sistema hidropônico NFT utilizando água salina do Semiárido - PE e rejeito de dessalinizador. Revista Brasileira de Ciências Agrárias, Recife, v. 6, n. 1, p.147-155, 2011.

SILVA, F. V. Cultivo Hidropônico de Rúcula (Eruca sativa Mill) utilizando águas salinas. 2009. 69 f. Tese (Doutorado em Agronomia) - Escola Superior de Agronomia "Luiz de Queiroz", Universidade de São Paulo, Piracicaba, 2009.

SOARES, T. M.; SILVA, E. F. F.; DUARTE, S. N.; MELO, R. F.; JORGE, C. A.; MARIA, E. M. B. Produção de alface utilizando águas salinas em sistema hidropônico. Irriga, Botucatu, v. 12, n. 2, p.235-248, 2007.

TAVARES, A. C. S. Manejo da fertirrigação e controle de salinidade para a cultura do pimentão (Capsicum annum) utilizando medidores de íons na solução do substrato. 2005. 101 f. Dissertação (Mestrado em Agronomia) - Escola Superior de Agronomia "Luiz de Queiroz", Universidade de São Paulo, Piracicaba, 2005.

TRAVASSOS, K. D.; GHEYI, H. R.; SOARES, F. A. L.; BARROS, H. M. M.; DIAS, N. S.; UYEDA, C. A.; SILVA, F. V. Crescimento e desenvolvimento de variedades de girassol irrigado com água salina. Irriga, Botucatu, edição especial, p.324-339, 2012. 